\title{
Assessing the impact of the European resilience curriculum in preschool, early and late primary school children
}

School Psychology International 2021, Vol. 42(5) 539-566 (C) The Author(s) 2021 Article reuse guidelines: sagepub.com/journals-permissions DOI: 10.1 I77/0 I 4303432 II025075 journals.sagepub.com/home/spi

@SAGE

\section{Celeste Simões $\mathbb{D}$}

Aventura Social, Faculdade de Motricidade Humana, Universidade de Lisboa, Portugal; Departamento de Educação, Ciências Sociais e Humanidades, Faculdade de Motricidade Humana, Universidade de Lisboa, Portugal; Instituto de Saúde Ambiental (ISAMB), Faculdade de Medicina, Universidade de Lisboa, Portugal

\section{Anabela C. Santos $\mathbb{D}$}

Aventura Social, Faculdade de Motricidade Humana, Universidade de Lisboa, Portugal; Departamento de Educação, Ciências Sociais e Humanidades, Faculdade de Motricidade Humana, Universidade de Lisboa, Portugal; Instituto de Saúde Ambiental (ISAMB), Faculdade de Medicina, Universidade de Lisboa, Portugal; ISCTE Instituto Universitário de Lisboa (IUL), CIS-IUL, Portugal

\section{Paula Lebre}

Aventura Social, Faculdade de Motricidade Humana, Universidade de Lisboa, Portugal; Departamento de Educação, Ciências Sociais e Humanidades, Faculdade de Motricidade Humana, Universidade de Lisboa, Portugal; ISCTE - Instituto Universitário de Lisboa (IUL), CIS-IUL, Portugal

\section{João R. Daniel (1)}

William James Center for Research, ISPA - Instituto Universitário, Portugal

\section{Corresponding author:}

Celeste Simões, Faculdade de Motricidade Humana, Estrada da Costa, 1499-002 Cruz Quebrada, Portugal. Email: csimoes@fmh.ulisboa.pt 


\title{
Cátia Branquinho
}

Aventura Social, Faculdade de Motricidade Humana, Universidade de Lisboa, Portugal; Departamento de Educação, Ciências Sociais e Humanidades, Faculdade de Motricidade Humana, Universidade de Lisboa, Portugal; Instituto de Saúde Ambiental (ISAMB), Faculdade de Medicina, Universidade de Lisboa, Portugal

\section{Tânia Gaspar}

Aventura Social, Faculdade de Motricidade Humana, Universidade de Lisboa, Portugal; Instituto de Saúde Ambiental (ISAMB), Faculdade de Medicina, Universidade de Lisboa, Portugal; Escola de Psicologia, Universidade Lusíada, CLISSIS, Portugal

\section{Margarida G. de Matos}

Aventura Social, Faculdade de Motricidade Humana, Universidade de Lisboa, Portugal; Departamento de Educação, Ciências Sociais e Humanidades, Faculdade de Motricidade Humana, Universidade de Lisboa, Portugal; Instituto de Saúde Ambiental (ISAMB), Faculdade de Medicina, Universidade de Lisboa, Portugal

\begin{abstract}
Resilience is an individual's ability to adapt successfully to and persevere during and after significant challenges. Resilience programmes based on a socioemotional learning approach have been associated with an increase in protective factors (e.g., prosocial competencies), improvements in physical and mental health, and a decrease in internalised and externalised symptoms. The present study aimed to evaluate the impact of the RESCUR curriculum implemented in Portuguese schools on students' academic, behavioural, and socioemotional outcomes, based on child and teacher reports. Participants included I,084 children (53.2\% male) aged 3-I5 ( $M=7.24$, $S D=2.3 \mathrm{I})$. A quasi-experimental study compared outcomes for an experimental intervention group (AIG) with a waiting list control group (WG). The results showed the RESCUR programme decreased mental health difficulties while increasing both prosocial behaviours and well-being. In addition, academic performance increased for those in preschool after implementation. Both teachers and children consistently reported positive behavioural changes in resilience-related competencies after implementing RESCUR. Our findings contribute to the recent research on the potential of RESCUR to address key socioemotional competencies and improve relevant protective factors. Study limitations and future recommendations are addressed.
\end{abstract}




\section{Keywords}

mental health, school-based approach, social and emotional learning, resilience, universal prevention

Resilience is an individual's ability to adapt and persevere in the face of significant challenges that threaten their functioning or development (Masten, 2018). Health promotion efforts often address it (Simões, 2015), and resilience training is a core part of the World Health Organization's (WHO's) Health 2020 campaign and the United Nations' Sustainable Development Goals (WHO, 2017).

Resilience is important when considering that all individuals face different challenges during their lives. These can range from developmental challenges to those that come from environmental risks and negative events, such as poverty, abuse, neglect, or household dysfunctions, which can compromise positive life trajectory (Larkin et al., 2012). This is especially harmful when several stressors accumulate (Kassis et al., 2018; Xiong et al., 2020). Protective actions can mitigate the negative effects of such risks.

In the last two decades, there has been a shift away from a deficit perspective to an asset perspective, focusing on people's and communities' strengths, participation, and well-being (Matos \& Simões, 2016). The resilience process combines resources and skills that enable us to cope with adversity and protect our health and well-being (WHO, 2017). As such, professionals in education should value and embrace the creation of learning opportunities and supportive contexts to help children and young people deal with challenges and adversities.

\section{Resilience-focused interventions}

Resilience interventions originate from the Social Emotional Learning (SEL) approach, which involves the development of fundamental skills such as the ability to recognise and manage emotions, solve problems, and establish positive relationships with others (Collaborative for Academic, Social, and Emotional Learning, 2003; Weissberg \& Cascarino, 2013). There is growing awareness of the benefits of curriculum-based SEL programmes as stated by reviews of programmes that show significant positive effects on children's social and emotional development (Durlak et al., 2011). Specifically, there is evidence of a decrease in externalising and internalising problems and gains in prosocial behaviours and academic performance (Carroll et al., 2020; Corcoran et al., 2018), with positive long-term outcomes related to high school graduation, healthy relationships, mental health, reduced criminal behaviour, or engaged citizenship (Weissberg et al., 2015).

The evaluation of SEL programmes shows that SEL is more effective under a comprehensive, multi-year, and multi-component approach (Zins et al., 2004). Moreover, effective programmes use a sequenced training approach, known as the 
SAFE (Sequenced, Active, Focused, Explicit) approach (Durlak et al., 2011). Schoolbased universal interventions that use the SAFE approach produce significant effects with respect to a larger range of outcomes (skills, attitudes, social behaviour, conduct problems, emotional distress, and academic performance; Durlak et al., 2011).

Resilience-focused interventions also show the potential to promote positive developmental outcomes (Brownlee et al., 2013). Studies have indicated that such interventions lead to gains in protective factors, increased physical and mental health (Forbes \& Fikretoglu, 2018), improved ability to manage daily stressors (FenwickSmith et al., 2018), improved emotion regulation, and decreases in negative emotions (Rich et al., 2019). Other studies have also found a reduction of depressive symptoms, internalising problems, externalising problems, and general psychological distress (Dray et al., 2017). Nevertheless, meta-analytic studies show that benefits vary according to gender, age, and outcome (Durlak et al., 2011; Leppin et al., 2014) as well as the risk levels children face in their lives (Suntheimer \& Wolf, 2020).

Implementation factors are also determinants of the success of interventions. Aspects such as the length of the programme/number of sessions, teacher involvement, or changes and adaptations in the programmes can make a difference in efficacy. Although some studies found that the length of the intervention did not impact the number of attained outcomes (Fenwick-Smith et al., 2018), others highlight that multiple sessions grant the time needed for learning and practising new skills (Forbes \& Fikretoglu, 2018). Teacher involvement in programme delivery is considered a key feature associated with positive results, especially when support and training are provided (Fenwick-Smith et al., 2018). Finally, teachers' knowledge about their students' needs and resources allows the activities to be adapted to foster engagement and maintain the quality of the programme under real-life conditions (Harnett \& Dadds, 2004).

\section{RESCUR: A resilience curriculum}

RESCUR is a universal curriculum that promotes resilience in early education and primary schools (Cefai et al., 2014). A European team developed the curriculum bearing in mind the cultural differences within the European context (Cefai et al., 2015). The main purpose of RESCUR is to enable children, especially the most vulnerable children, to use their resources to overcome obstacles and continue to grow and prosper (Cefai et al., 2015). RESCUR is grounded in an ecological framework that considers school as well as the children's families and extended community. The curriculum acts through a direct path: the resilience-related competencies taught by the teacher; and an indirect path: the processes triggered by ecological changes that curriculum implementation can have in the classroom, in the whole school (climate, relationships, attitudes, and behaviours), as well as in family and community contexts. This framework encompasses a set of key principles a developmental, inclusive, and responsive approach to individual needs, a spiral structure increasing in complexity as the child develops, the use of evidence-based strategies 
for resilience promotion (e.g., the SAFE approach), and formative assessments by both the classroom teacher and students (Cefai et al., 2015).

RESCUR includes six themes: Theme 1: communication skills, Theme 2: relationship management and maintenance, Theme 3: positive mindset, Theme 4: selfdetermination, Theme 5: personal strengths, and Theme 6: turning challenges into opportunities. These themes are addressed in a set of three activity manuals (which are keyed to age), with specific learning goals and outcomes that follow a common structure: mindfulness activity; story with group reflection and discussion; practical hands-on activities; and a take-home activity including handouts for parents (further details in Cefai et al., 2015).

A large RESCUR pilot was conducted in the six partner countries of the consortium responsible for the curriculum development over six weeks in 205 classrooms, including 2,895 students and 199 trained teachers. The evaluation of data from 1,935 students, including information about student interests, programme usability, and curriculum suitability, showed positive results, both from the teacher and student perspectives (Cefai et al., 2015). An extended implementation and evaluation of the curriculum's impact was conducted in Malta, Greece, and Portugal. The results of a 1-year implementation of RESCUR in Malta (Cefai et al., 2018) showed gains in resilience competencies, prosocial behaviour, and learning engagement, but no changes in internalised and externalised problems. In Greece, the study focussed on parent views, with results showing that RESCUR was effective overall in promoting communication skills, self-determination skills, and healthy relationships between parents and children (Matsopoulos et al., 2020).

\section{The present study}

This study presents the results of RESCUR curriculum implementation in Portugal. We evaluate the impact of the 1-year implementation of RESCUR using a multilevel analysis that allows the researchers to (a) verify the impact of RESCUR on a set of outcomes (prosocial behaviour, social maladjustment and mental health difficulties, resilience, health-related quality of life and academic performance, prosocial behaviour, total difficulties, and academic performance); (b) verify improvements in resilience-related competencies between the two groups; and (c) verify the dosage impact on the outcomes by comparing a group with an average of 15.01 sessions $(S D=7.43)$ with a group with an average of 30.28 sessions $(S D=6.61)$.

\section{Method}

\section{Design}

Councils and schools in the Lisbon metropolitan area took part in the project. After the establishment of a partnership with teacher training centres, 123 teachers and school staff received a 25-hour accredited course with theoretical and practical 
components for implementing RESCUR in four separate courses (one teacher's class was from Coimbra region). After the pre-test, 64 teachers from 27 different schools taught RESCUR to 1,692 children. RESCUR's target population is children in preschool and primary school (Grades 0-6). However, teachers from upper grades (7-9) asked to be part of the training and implementation. The implementation in these grades was performed under different conditions (i.e., the children had special education needs, and implementation was performed in small groups instead of with the entire class). Thus, the present study did not include these participants (see Figure 1).

Two groups were established according to logistics: the annual intervention group (AIG) and the waiting group (WG). Teachers who were transferred to a new school or who had new classes assigned were part of the WG to give them time to get to know the children and only then perform assessments. The University Ethics Committee, the Commission for the Protection of Children and Young People, the board of directors of participating schools and the city councils where the schools were located approved all procedures. Finally, parents or guardians authorised their child's participation, and the children themselves gave verbal consent.

\section{Participants}

A total of 1084 children (53.2\% male) from 57 classrooms in 22 different schools were included in the present study. Participating children were between 4 and 15 years old $(M=7.24, S D=2.31)$ and mostly of Portuguese nationality $(94 \%)$. The distribution of participants across school years was $30.6 \%$ preschool, $54.0 \%$ early primary (grades $1-4$ ), and $15.4 \%$ late primary (grades 5-6). No significant group differences were found for the demographic variables (for details regarding the demographic characteristics and the distribution of participants by implementation group, see Table S1 in the Supplemental material).

\section{Implementation}

The RESCUR implementation took place between September 2017 and July 2018. Sessions were 45-60 minutes long and were delivered weekly to all children in the class following the steps defined in the curriculum (further details in Cefai et al., 2015). The data collection took place on three occasions. Teachers in the AIG group were instructed to implement around 15 sessions (one session per week) after the first assessment plus around 15 more sessions between the second assessment and the third (final) assessment, whereas teachers in the WG were instructed to implement about 15 sessions only after the second assessment (also one session per week). See Figure 2 for the implementation design diagram. Teachers in the AIG implemented, on average, 30.58 sessions $(S D=6.96)$, whereas teachers in the WG implemented 14.69 sessions $(S D=7.02)$. 


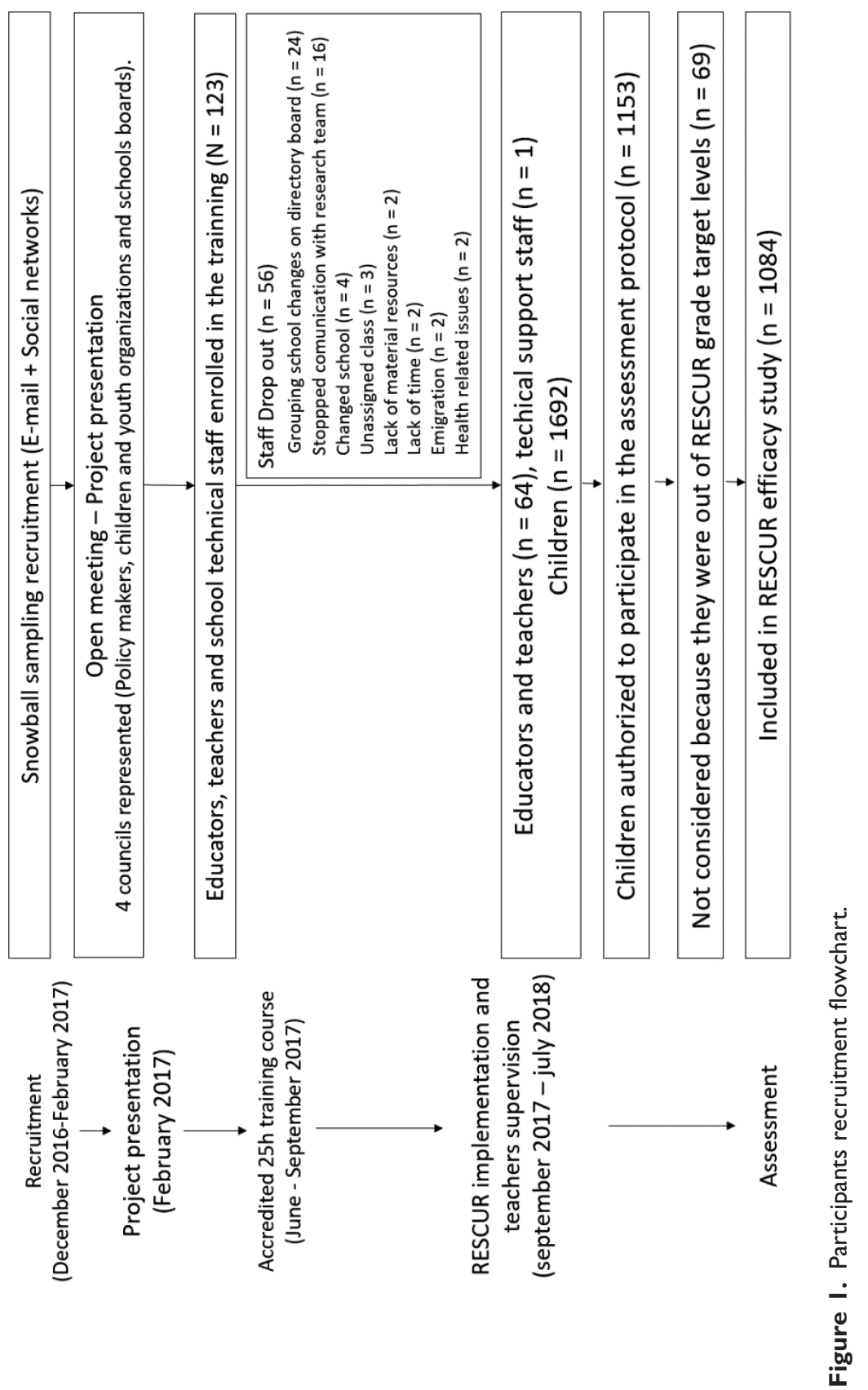




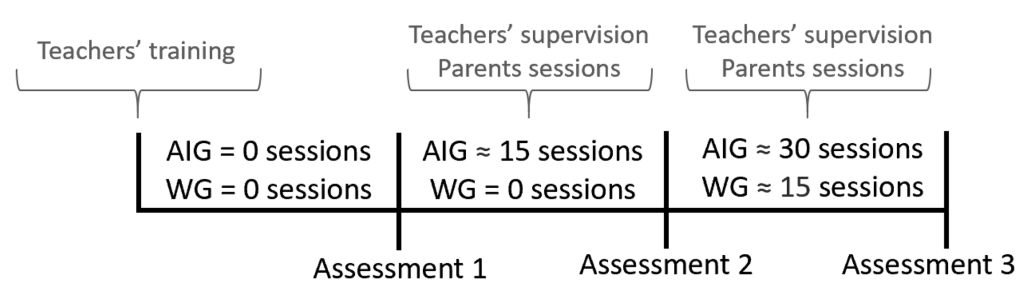

Figure 2. Implementation design. Note. AIG: annual implementation group; WG: waiting group.

Three supervision sessions were delivered over the course of implementation, as well as two parent sessions, wherein parents were presented with the curriculum and ways they could promote resilience daily. Implementation fidelity and characteristics were assessed through a questionnaire (see Exhibit S2 in the Supplemental material), reinforced, and jointly discussed throughout the process in the supervision sessions.

All RESCUR materials (further details in Cefai et al., 2015) were freely provided. The project ended in each group with a week-long arts exhibition and a public session in which the community was invited to be present. This part of the project intended to include and reach the community, which is an essential part of fostering child resilience (Ungar et al., 2014).

\section{Measures}

The evaluation plan included self-report measures for teachers and students. Teachers rated the students' overall risk exposure, reported the children's academic performance, and answered the Strengths and Difficulties Questionnaire (SDQ) as well as the RESCUR checklist reduced version (RCRV). Students in primary school answered the RCRV, the Child and Youth Resilience Measure (CYRM12) and the Health-Related Quality of Life Questionnaire for Children and Adolescents (KIDSCREEN), and only those in late primary school (grades 5-6) responded to the SDQ. Reliability values for the three administrations are identified as $1 \alpha, 2 \alpha$ and $3 \alpha$ for the first, second and third assessments, respectively. Also, interclass correlation values (ICC1 and ICC2) were analysed for each measure at each time point, with values ranging from moderate to strong internal consistency, except for KIDSCREEN at the second assessment (see Table S6 in the Supplementary materials).

Strengths and Difficulties Questionnaire Portuguese version (SDQ; Fleitlich et al., 2004) was used to evaluate changes in child behaviour. The SDQ has 25 items that were answered on a 3-point scale from 0 (not true) to 2 (certainly true), with higher values representing higher social and emotional competencies or higher difficulties. Changes in social and emotional competencies were evaluated via the SDQ Prosocial Behaviour subscale with five items (e.g., "Helpful if someone is hurt/I am helpful if someone is hurt"). Social maladjustment and mental health 
difficulties were evaluated via the SDQ Total Difficulties score with 20 items across four subdimensions, including (a) Emotional Symptoms (e.g. "Often unhappy, downhearted/I am often unhappy"); (b) Conduct Problems (e.g., "Often has temper tantrums or hot tempers/I get very angry"); (c) Hyperactivity/Inattention (e.g., "Easily distracted, concentration wanders/I am easily distracted"); and (d) Peer Problems (e.g., "Rather solitary, tends to play alone/I am usually on my own"). The internal consistency of the SDQ teacher version across administrations was as follows: SDQ Total Difficulties $(1 \alpha=.85,2 \alpha=.85,3 \alpha=.86)$ and Prosocial Behaviour $(1 \alpha=.90,2 \alpha=.90,3 \alpha=.90)$. Reliability scores for the student versions across administrations were: SDQ Total Difficulties $(1 \alpha=.77,2 \alpha=.83,3 \alpha=.82)$ and Prosocial Behaviour $(1 \alpha=.70,2 \alpha=.74,3 \alpha=.69)$.

Academic performance data were collected from the school records provided by teachers. The teachers evaluated students on a five-point scale from 1 (insufficient) to 5 (excellent). A median score for the student's academic performance for each subject was computed. The academic performance data for preschool included Portuguese, Mathematics, Artistic Expression, and Physical Education. For primary school (grades 1-6) the courses include the above plus Foreign Language, and Estudo do Meio, a course which seeks to provide a cohesive concept of society and nature through the combination of various scientific disciplines (such as Natural Sciences, Geography and History) plus citizenship. Internal consistency was good for academic performance both at preschool $(1 \alpha=.87,2 \alpha=.89,3 \alpha=.86)$ and in primary school $(1 \alpha=.93,2 \alpha=.90,3 \alpha=.88)$.

KIDSCREEN-10 Portuguese version (Matos et al., 2012) was used for the assessment of children's perceived quality of life. KIDSCREEN-10 is a European scale with 10 items (e.g., "I feel fit and well", "I do things in my free time") and was answered on a 5-point scale from 1 (never; not at all) to 5 (always; extremely). Internal reliability was acceptable $(1 \alpha=.71,2 \alpha=.65,3 \alpha=.74)$.

CYRM-12 was used to assess resilience (Liebenberg et al., 2013). This scale was derived from the CYRM-28, which has been used in Portugal (Ferreira, 2014). CYRM-12 has 12 items (e.g., "Is doing well in school important to you?", "When things don't go your way, can you fix it without hurting yourself or other people, for example without hitting others or saying nasty things?") that were answered on a 3-point scale from 1 (does not describe me at all) to 3 (describes me a lot). The measure presented very good reliability at all three assessments $(1 \alpha=.93,2 \alpha=.93,3 \alpha=.91)$.

RCRV is based on the RESCUR Assessment Checklist (Cefai et al., 2015) with the teachers and primary school children answering 42 items at the end of each RESCUR theme implementation to identify the changes that occurred in the children's behaviour. The scale has six dimensions: Theme 1: communication skills (e.g., "I/the child can communicate ideas, cooperate and negotiate"), Theme 2: relationship management and maintenance (e.g., "I/The child can share and work as a team"), Theme 3: positive mindset (e.g., "I/The child can distinguish between positive and negative thinking"), Theme 4: self-determination (e.g., "I/The child can define a problem and think of creative solutions"), Theme 5: personal 
strengths (e.g., "I/The child discovered positive things about myself and I like myself better"), and Theme 6: turning challenges into opportunities (e.g., "I/The child can deal with difficulties showing courage and persistence"). Each theme has six items (except the sixth, which has 12 items) with the teacher version using a 6point scale (0-not observed; 5-yes, with no doubt) while the student version using a 3 -point scale (1-worse/less; 3-better/more). Internal consistency was very good for all dimensions for the teacher version (Theme $1 \alpha=.93$; Theme $2 \alpha=.95$; Theme 3 $\alpha=.95$; Theme $4 \alpha=.95$; Theme $5 \alpha=.96$; Theme $6 \alpha=.91)$. The internal consistency was acceptable for the student version (Theme $1 \alpha=.70$; Theme $2 \alpha=.69$; Theme $3 \alpha=.66$; Theme $4 \alpha=.69$; Theme $5 \alpha=.76$; Theme $6 \alpha=.85$ ).

The overall risk assessed risk factors, namely the exposure to adverse childhood experiences, and its magnitude in the children's lives as perceived by teachers. First, teachers were provided with a list of 10 items and asked to identify which were present (e.g., poverty, parental education level, parental mental health issues). Then they were asked to classify the risk level for the child on a 5-point scale from 0 (lack of risk factors) to 4 (high-risk level). Teachers were invited to write other identified risk factors.

\section{Data analysis}

We used multilevel regression models to compare the outcomes of the two groups (AIG vs. WG) across the three assessments, with repeated measures as level 1, students as level 2, and classrooms as level 3. The small number of different schools did not warrant a fourth level in the regression models.

Group differences were assessed while controlling for the following covariates: gender, school level, risk level (grand mean centred), and number of sessions (the actual number of sessions implemented by each teacher; grand mean centred). The inclusion of covariates was based on two criteria: significant correlation with the outcomes and literature support.

The models' regression intercepts represent estimated means for the average student at the first assessment. The coding scheme used for the categorical variables can be seen in Table S4 of the Supplemental material. The alpha level of significance was set at .05 for all analyses (two-tailed). Models were run using lmerTest (3.1-3) package (Kuznetsova et al., 2016) in $\mathrm{R}$ version 4.0.3 (R Core Team, 2020).

Prior to multilevel modelling, we imputed missing data (details relative to the percentage of missing data are in Table S5 in the Supplemental material) using multivariate imputation by chained equations, using mice (3.2.0; van Buuren \& Groothuis-Oudshoorn, 2011) and miceadds (3.11-6; Robitzsch \& Grund, 2021) R packages. Because of the multilevel structure of our data, we followed the fully conditional specification 2-level wide approach (FCS-2L-wide) detailed in van Buuren (2011). We set the number of iterations in the mice algorithm to 10 and created 20 different imputed datasets. We used the $21 . \mathrm{pmm}$ imputation method for lower-level variables and 2lonly.pmm for the number of sessions (classroom level 
variable). After imputation, each dataset was analysed separately, and model estimates were subsequently pooled. For RESCUR themes and KIDSCREEN-10 data, no imputation was done because of the high proportion of missing values.

\section{Results}

Table 1 presents the descriptive statistics for the different variables. In the analysis, all multilevel regression model estimates controlled for gender, risk level, school level, and the number of sessions. The only exception is the Strengths and Difficulties questionnaire students' version, which did not include school level.

\section{Strengths and difficulties questionnaire: Teachers}

Multilevel regression model estimates for SDQ Total Difficulties and Prosocial Behaviour (Table 2, Figure 3), controlling for gender, risk level, school level, and the number of sessions, showed that teachers reported AIG and WG students to have similar scores at the onset of the study (Assessment 1 estimated mean differences - Total Difficulties: $\beta 8=-0.29, p=.222$; Prosocial Behaviour: $\beta 8=0.13$, $p=.343$ ). On the following assessments significant overall changes were found, with Total Difficulties scores decreasing over time (estimated mean differences Assessment2: $\quad \beta 1=-0.15, \quad p<.001 ; \quad$ Assessment3: $\beta 2=-0.33, \quad p<.001)$ and Prosocial Behaviour scores increasing over time (estimated mean differences Assessment 2: $\beta 1=0.07, p<.001$; Stage 3: $\beta 2=0.11, p<.007)$. Nevertheless, these changes were qualified by a group interaction, with AIG students, at the second assessment, scoring lower in Total Difficulties (Assessment 2 estimated mean differences: $\beta 9=-0.36, p<.001)$ and higher in Prosocial Behaviour than WG students (Assessment 2 estimated mean differences: $\beta 9=0.10, p=.021$ ).

\section{Strengths and difficulties questionnaire: Students (late primary students)}

Multilevel regression model estimates for Total Difficulties and Prosocial Behaviour (see Figure 4 and Table S7 in the Supplemental material), controlling for gender, risk level, and number of sessions, showed that the late primary students (grade 5 - 6) in AIG and WG reported similar scores at the onset of the study (Assessment 1 estimated mean differences - Total Difficulties: $\beta 8=-0.25, p=.751$; Prosocial Behaviour: $\beta 8=0.13, p=.643$ ). No overall mean changes were found at the subsequent assessments, neither for Total Difficulties (estimated mean differences - Assessment 2: $\beta 1=0.07, p=.484$; Assessment 3: $\beta 2=-0.12, p=.315$ ) nor for Prosocial Behaviour (estimated mean differences - Assessment 2: $\beta 1=-0.04$, $p=.290$; Assessment 3: $\beta 2=-0.03, p=.569$ ). Also, no significant interactions were found between group and assessment, neither for Total Difficulties (Assessment 2 estimated mean differences: $\beta 7=-0.32, p=.131$; Assessment 3 estimated mean differences: $\beta 8=-0.07, p=.823$ ), nor for Prosocial Behaviour (Assessment 2 estimated mean differences: $\beta 7=0.04, p=.629$; Assessment 3 estimated mean differences: $\beta 8=-0.05, p=.641$ ). 


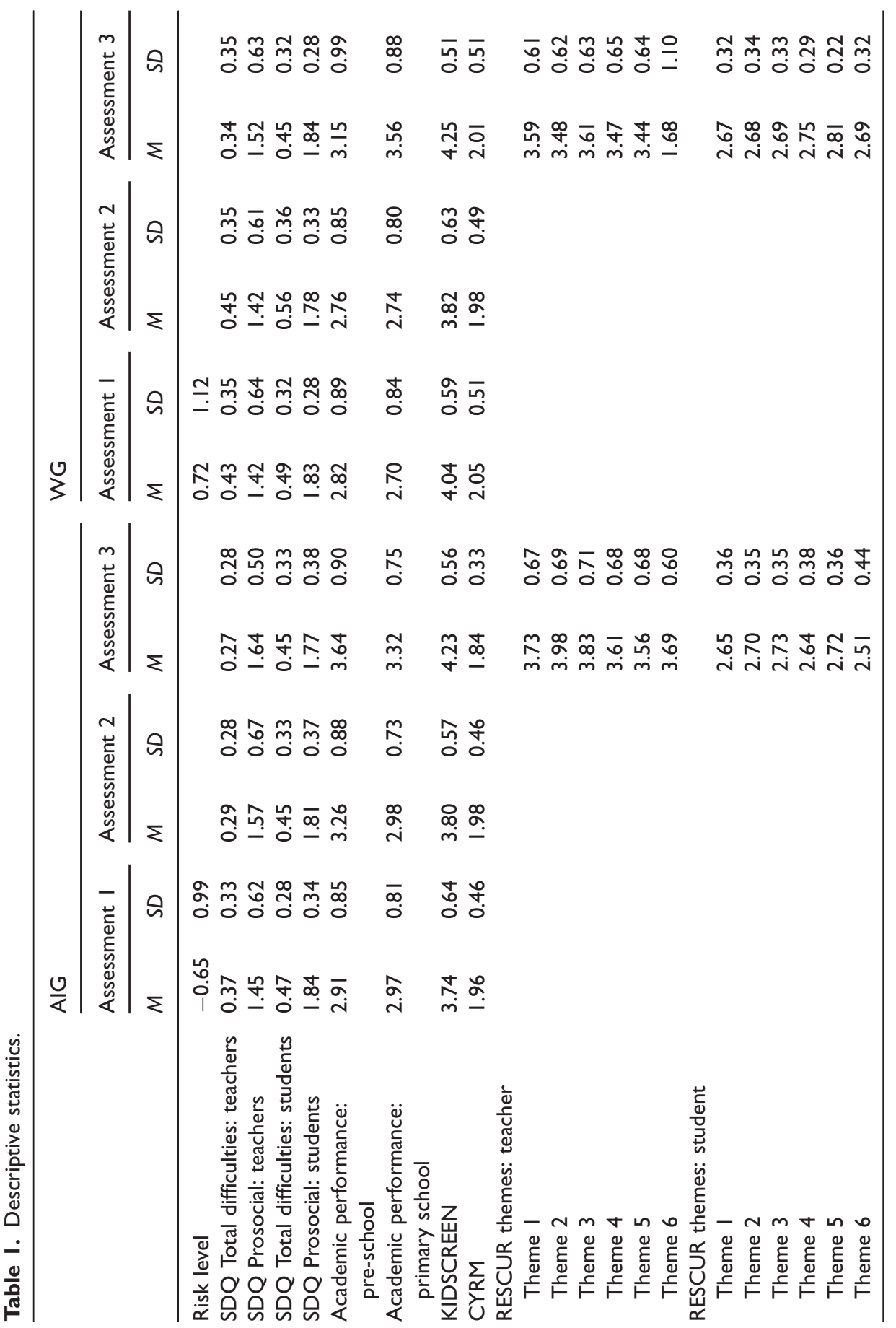


Table 2. Multilevel model estimates for SDQ: Teachers.

\begin{tabular}{|c|c|c|c|c|c|c|}
\hline & \multicolumn{3}{|c|}{ Total difficulties } & \multicolumn{3}{|c|}{ Prosocial behaviour } \\
\hline & $\beta$ & SE & $p$ & $\beta$ & SE & $p$ \\
\hline$\beta 0$ Intercept & 1.47 & 0.08 & $<.001$ & 1.43 & 0.05 & $<.001$ \\
\hline \multicolumn{7}{|l|}{ Level I variables } \\
\hline$\beta 1$ Assessment 2 & -0.15 & 0.04 & $<.001$ & 0.07 & 0.02 & $<.001$ \\
\hline$\beta 2$ Assessment 3 & -0.33 & 0.08 & $<.001$ & 0.11 & 0.04 & .007 \\
\hline \multicolumn{7}{|l|}{ Level 2 variables } \\
\hline$\beta 3$ Gender $(+)$ & -0.33 & 0.05 & $<.001$ & 0.23 & 0.03 & $<.001$ \\
\hline$\beta 4$ Risk level & 0.54 & 0.03 & $<.001$ & -0.11 & 0.01 & $<.001$ \\
\hline \multicolumn{7}{|l|}{ Level 3 variables } \\
\hline$\beta 5$ School level (preschool) & -0.16 & 0.20 & .413 & -0.01 & 0.06 & .902 \\
\hline$\beta 6$ School level (early primary) & 0.62 & 0.18 & $<.001$ & 0.01 & 0.06 & .826 \\
\hline$\beta 7$ Number of sessions & 0.01 & 0.01 & .643 & -0.01 & 0.01 & .400 \\
\hline$\beta 8$ Implementation group (AIG) & -0.29 & 0.23 & .222 & 0.13 & 0.13 & .343 \\
\hline \multicolumn{7}{|l|}{ Cross-level interactions } \\
\hline$\beta 9$ Assessment $2 \times$ Group (AIG ) & -0.36 & 0.08 & $<.001$ & 0.10 & 0.04 & .021 \\
\hline$\beta I 0$ Assessment $3 \times$ Group (AIG) & -0.09 & 0.17 & .628 & 0.13 & 0.10 & .205 \\
\hline$\sigma$ Student/Classroom & 0.74 & & & 0.33 & & \\
\hline$\sigma$ Classroom & 0.40 & & & 0.28 & & \\
\hline$\sigma$ Residual & 0.68 & & & 0.35 & & \\
\hline
\end{tabular}

Note. 3252 observation, 1084 students, 57 classrooms; AIG - annual implementation group.

\section{Academic performance}

Multilevel regression model estimates for Academic Performance (Table 3; Figure 5), controlling for gender, risk level, number of sessions, and school level showed that preschool and primary school children in AIG and WG had similar scores at the study onset (Assessment 1 estimated mean differences - preschool: $\beta 7=-0.24, p=.578$; school: $\beta 7=0.30, p=.059)$. Both preschool and primary school children showed overall gains at the subsequent assessments, albeit only at the third assessment for primary school children (estimated mean differences Assessment 2 preschool: $\beta 1=0.17, p=.001$; Assessment 3 preschool: $\beta 2=0.60$, $p<.001$; Assessment 2 school: $\beta 1=0.04, \quad p=.079$; Assessment 3 school: $\beta 2=0.54, p<.001)$. Nevertheless, these changes were qualified by different group$\times$ time interactions. While preschool children in the AIG improved more than children in the WG at the second assessment (Assessment 2 estimated mean differences: $\beta 8=0.40, p<.001$ ), but not at the third (Assessment 3 estimated mean differences: $\beta 9=0.29, p=.146)$; school children in both groups had similar scores at the second assessment (Assessment 2 estimated mean differences: $\beta 8=-0.05, p=.301)$, but AIG children improved less than WG ones at the third assessment (Assessment 3 estimated mean differences: $\beta 9=-0.36, p=.001$ ). 


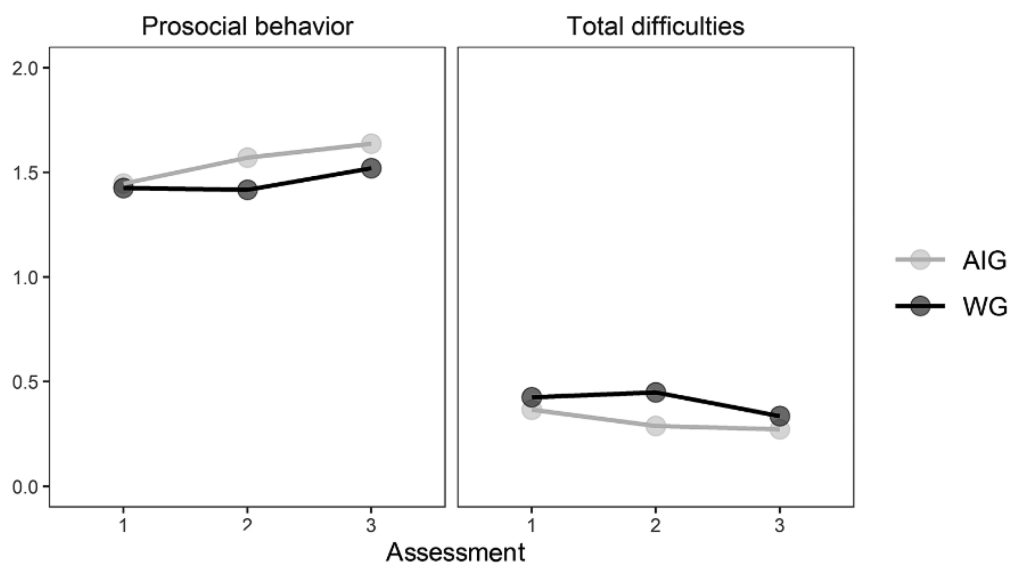

Figure 3. Strengths and difficulties questionnaire - teachers: Total difficulties and Prosocial behaviour mean scores over time and across groups. Note. AIG: annual implementation group; WG: waiting group.

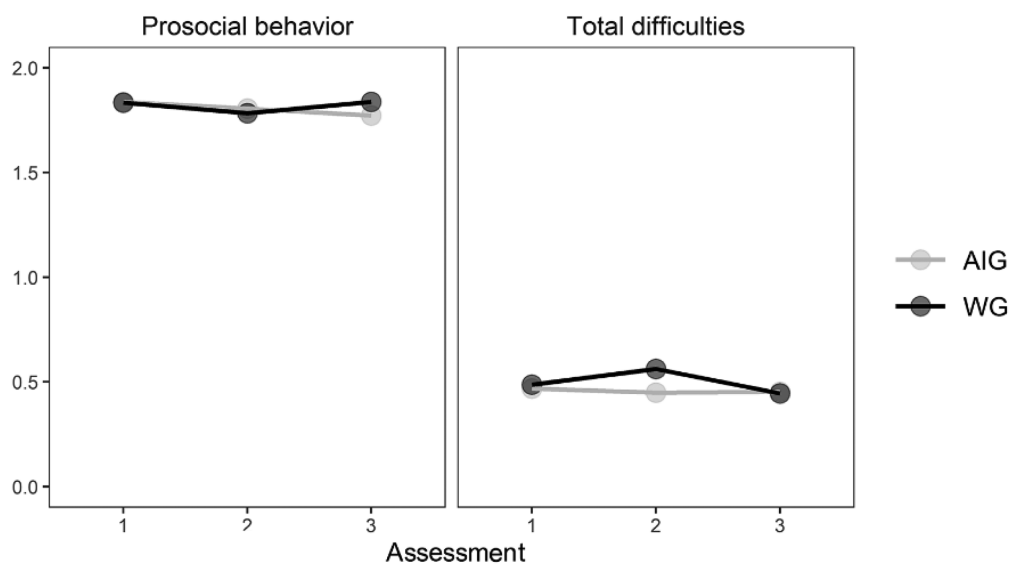

Figure 4. Strengths and difficulties questionnaire - students (late primary): Total difficulties and Prosocial behaviour mean scores over time and across groups. Note. AIG: annual implementation group; WG: waiting group.

Health-related quality of life questionnaire for children and adolescents: Students (early primary and late primary)

Multilevel regression model estimates for KIDSCREEN-10 (Table 4; Figure 6), controlling for gender, risk level, number of sessions, and school level show that AIG and WG children had similar scores at the onset of the study (Assessment 1 estimated mean differences: $\beta 7=-0.08, p=.407$ ). Overall changes (higher scores) 
Table 3. Multilevel model estimates for academic performance.

\begin{tabular}{|c|c|c|c|c|c|c|}
\hline & \multicolumn{3}{|c|}{ Pre-school } & \multicolumn{3}{|l|}{ School } \\
\hline & $\beta$ & $S E$ & $p$ & $\beta$ & SE & $p$ \\
\hline$\beta 0$ Intercept & 2.91 & 0.12 & $<.001$ & 2.82 & 0.06 & $<.001$ \\
\hline \multicolumn{7}{|l|}{ Level I variables } \\
\hline$\beta \mid$ Assessment 2 & 0.17 & 0.05 & .001 & 0.04 & 0.02 & .079 \\
\hline$\beta 2$ Assessment 3 & 0.60 & 0.09 & $<.001$ & 0.54 & 0.04 & $<.001$ \\
\hline \multicolumn{7}{|l|}{ Level 2 variables } \\
\hline$\beta 3$ Gender $(+)$ & 0.19 & 0.08 & .023 & 0.13 & 0.04 & .001 \\
\hline$\beta 4$ Risk level & -0.27 & 0.04 & $<.001$ & -0.37 & 0.02 & $<.001$ \\
\hline \multicolumn{7}{|l|}{ Level 3 variables } \\
\hline$\beta 5$ School level (early primary) & & & & -0.01 & 0.13 & .960 \\
\hline$\beta 6$ Number of sessions & 0.01 & 0.01 & .453 & 0.00 & 0.01 & .931 \\
\hline$\beta 7$ Implementation group (AIG) & -0.24 & 0.43 & .578 & 0.30 & 0.16 & .059 \\
\hline \multicolumn{7}{|l|}{ Cross-level interactions } \\
\hline$\beta 8$ Assessment $2 \times$ Group (AIG ) & 0.40 & 0.11 & $<.001$ & -0.05 & 0.05 & .301 \\
\hline$\beta 9$ Assessment $3 \times$ Group (AIG) & 0.29 & 0.20 & .146 & -0.36 & 0.09 & .001 \\
\hline$\sigma$ Student/Classroom & 0.59 & & & 0.49 & & \\
\hline$\sigma$ Classroom & 0.34 & & & 0.26 & & \\
\hline$\sigma$ Residual & 0.49 & & & 0.38 & & \\
\hline
\end{tabular}

Note. Preschool: 996 observations, 332 children, 2I classrooms; school: 2256 observations, 752 students, 37 classrooms; AIG - annual implementation group.

were only observed for Assessment 3 (estimated mean differences: $\beta 2=0.46$, $p<.001$ ), but not for Assessment 2 (estimated mean differences: $\beta 1=-0.03$, $p=.314$ ). Significant interactions between group and assessment (Assessment 2 estimated mean differences: $\beta 8=0.19, p=.004$; Assessment 3 estimated mean differences: $\beta 9=0.28, p<.001$ ) show that AIG children increased their scores more than their WG counterparts in Assessments 2 and 3.

\section{Child and youth resilience measure: Students (early primary and late primary)}

Multilevel regression model estimates for CYRM (see Figure 7 and Table S8 in the Supplemental material), controlling for gender, risk level, number of sessions, and school level show that WG scored higher than their AIG counterparts at the study onset (Assessment 1 estimated mean differences: $\beta 7=0.06, p=.041$ ). The subsequent assessments found no overall mean changes, (estimated mean differences Assessment 2: $\beta 1=0.01, p=.606$; Assessment 3: $\beta 2=0.02, p=.055$ ), or significant interactions between group and assessment (Assessment 2 estimated mean differences: $\beta 8=-0.02, p=.399$; Assessment 3 estimated mean differences: $\beta 9=-0.02, p=.445)$. 


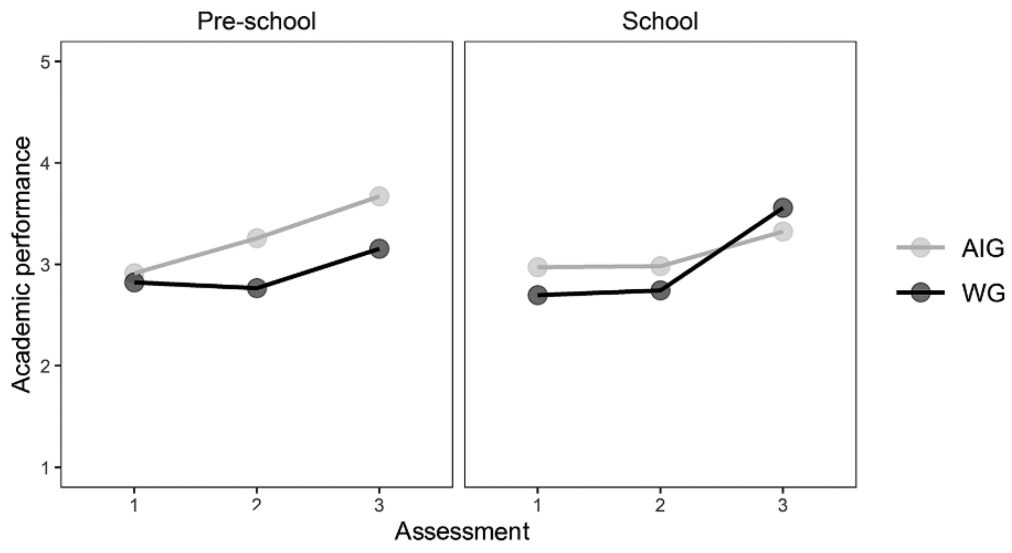

Figure 5. Academic performance mean scores over time and across groups for pre-school and school children. Note. AIG: annual implementation group; WG: waiting group.

Table 4. Multilevel model estimates for KIDSCREEN-I0 (early primary and late primary).

\begin{tabular}{lrrr}
\hline & $\beta$ & $S E$ & \multicolumn{1}{c}{$p$} \\
\hline$\beta 0$ Intercept & 3.91 & 0.04 & $<.001$ \\
Level I variables & & & .314 \\
$\beta$ I Assessment 2 & -0.03 & 0.03 & $<.001$ \\
$\beta 2$ Assessment 3 & 0.46 & 0.03 & .968 \\
Level 2 variables & & & $<.001$ \\
$\beta 3$ Gender (+) & 0.00 & 0.04 & $<.001$ \\
$\beta 4$ Risk level & -0.15 & 0.02 & .567 \\
Level 3 variables & & & .407 \\
$\beta 5$ School level (early primary) & -0.52 & 0.07 & .004 \\
$\beta 6$ Number of sessions & 0.00 & 0.01 & $<.001$ \\
$\beta 7$ Implementation group (AIG) & -0.08 & 0.10 & \\
Cross-level interactions & & & \\
$\beta 8$ Assessment 2 $\times$ Group (AIG) & 0.19 & 0.07 & \\
$\beta 9$ Assessment 3 $\times$ Group (AIG) & 0.28 & 0.07 & \\
$\sigma$ Student/Classroom & 0.32 & & \\
$\sigma$ Classroom & 0.08 & & \\
$\sigma$ Residual & 0.41 & & \\
\hline
\end{tabular}

Note. 1087 observations, 439 students, 23 classrooms; AIG - annual implementation group.

\section{RESCUR themes: Teachers}

Multilevel regression model estimates for RESCUR themes (Table 5), controlling for gender, risk level, number of sessions, and school-level) show that there was an overall group effect for Themes 2 and 6 (estimated mean difference - Theme 2: $\beta 6=0.64 p=.005$; Theme 6: $\beta 6=2.19, p=.041)$. 


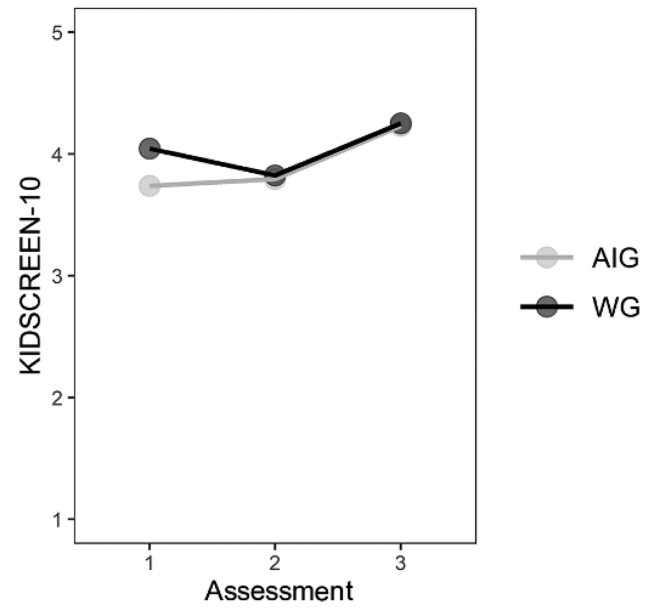

Figure 6. KIDS mean scores over time and across groups for school children. Note. AIG: annual implementation group; WG: waiting group.

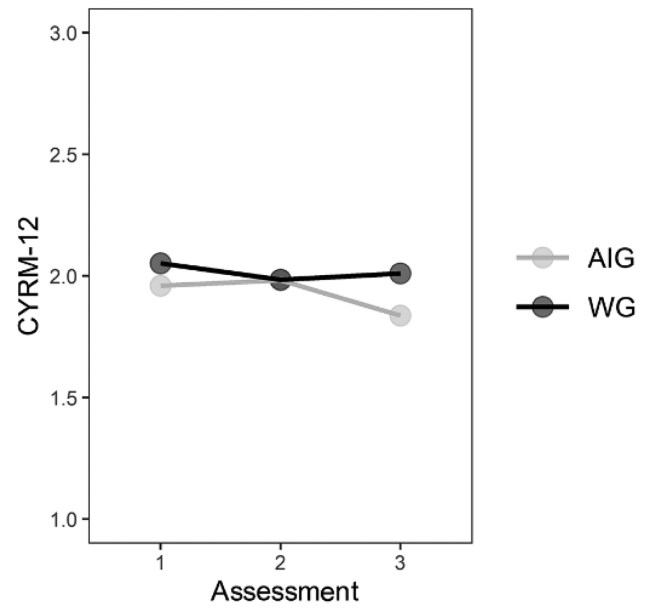

Figure 7. CYRM mean scores over time and across groups for school children. Note. AIG: annual implementation group; WG: waiting group.

\section{RESCUR themes: Students (early primary and late primary)}

Multilevel regression model estimates for RESCUR themes show that there was no overall group effect, controlling for gender, risk level, number of sessions, and school level (see Table S9 in the Supplemental material). 


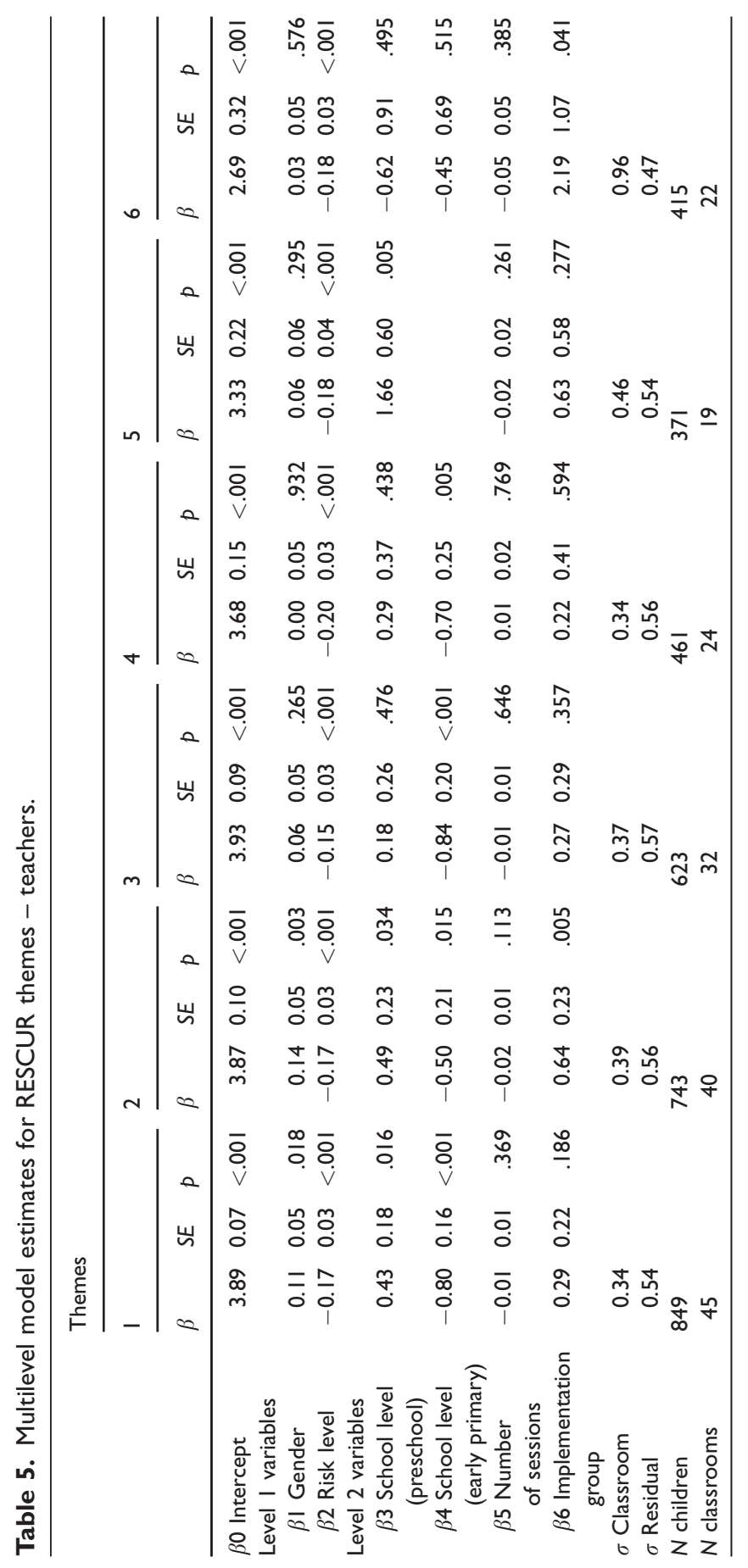




\section{Covariates}

Overall risk was the covariate that showed the greatest consistency, having significant relationships with all outcomes, although the strength of the association was variable. The overall risk was negatively associated with prosocial behaviour, health-related quality of life, resilience, and RESCUR themes, while it was positively associated with total difficulties. Some outcomes were significantly related to gender. Generally, female students had lower scores for mental health difficulties but higher scores for prosocial behaviours, academic performance, and resiliencerelated competencies (communication, relationships management and maintenance). The school-level covariate was introduced to account for the differences in development related to school grade and the usage of different RESCUR manuals. The early primary school level showed lower scores of resilience and healthrelated quality of life but higher scores in SDQ total difficulties according to teacher ratings. Finally, the number-of-sessions covariate was used to account for variability in the number of sessions each group had, but it was not significant in the model.

\section{Discussion}

This study evaluated the effect of RESCUR on mental health difficulties, prosocial behaviour, academic performance, quality of life, and resilience-related competencies, considering teacher and child perspectives. According to teachers' ratings, RESCUR contributed to a decrease in student mental health difficulties, mostly in the AIG. However, the WG also showed an improvement regarding mental health difficulties after RESCUR intervention. Our findings support previous research indicating that resilience-focused promotion can reduce general psychological distress (Dray et al., 2017) by diminishing internalising and externalising symptoms. At the final assessment, no differences between groups were found, reflecting gains for both groups. Thus, our results regarding prosocial behaviour were aligned with a similar RESCUR impact study (Cefai et al., 2018).

Regarding academic performance, the results showed improvements, especially for preschool children after the intervention. These results align with other studies (Corcoran et al., 2018; Durlak et al., 2011) that point to gains in academic performance associated with SEL programmes. Moreover, they also reflect developmental aspects that should be addressed in preventive research; specifically, the earlier the child gets opportunities to foster resilience and has contact with SEL programmes, the more pervasive positive outcomes will be (Cefai et al., 2018). Moreover, differences between groups were observed for all RESCUR resiliencerelated competencies. They were significant in the "relationship management and maintenance" theme, as well as the "turning challenges into opportunities" theme. The AIG group showed more gains, thus supporting the results of Cefai et al. (2018). 
The feedback from the teachers, parents and children was positive. In previous research, in which supervision sessions were analysed (Simões et al., 2020), teachers reported that they felt positive differences in the children's behaviours and socioemotional competencies, including greater autonomy, positive changes in class climate, decreases in aggressive behaviours, greater ability to calm down and to solve problems, and more prosocial behaviours (i.e., helping, sharing, protecting, listening). Additionally, the children and their parents also talked about these positive changes in the informal sessions (for more details see Simões et al., 2020). This is in line with the literature (Matsopoulos et al., 2020). However, student scores did not reflect a decrease in the SDQ total difficulties or show an increase in prosocial behaviour.

Students' perception of their mental health difficulties and prosocial behaviour were similar between groups and assessments. The maintenance of these values may be related to the fact that good psychological functioning was attained (Harnett \& Dadds, 2004), since low values were reported for mental health difficulties and high values (close to the maximum value possible) were reported for prosocial behaviour, thus reflecting floor and ceiling effects. Also, no differences between groups were observed for RESCUR themes according to students. Thus, overall, students felt improvements and that their resilience-related competencies changed for the better after RESCUR implementation.

Regarding health and well-being, differences were attained but only in the third assessment, with gains for both groups but higher scores for the AIG relative to the WG. This is relevant since RESCUR is a resilience-based programme, which involves a multidimensional perspective (Cefai et al., 2014, 2015). This type of programme facilitates child access to individual, relational, and contextual resources linked with better school connection and performance as well as overall mental and physical well-being (Ungar et al., 2019).

Regarding resilience, CYRM scores were slightly above the mean value, showing an adequate level of resilience throughout the year. The absence of statistical differences for the resilience measure may have had more to do with the nature of resilience in childhood, which can be observed through a host of positive academic and social behaviours such as good academic performance, the establishment and maintenance of healthy relationships, a sense of well-being, and the absence of internalising or externalising problems (Masten, 2018). As reported previously, these positive academic and social behaviours were present in our data. Also, the notion that socioemotional competencies are a condition for resilience manifestation is consistent with previous research (Fenwick-Smith et al., 2018; Forbes \& Fikretoglu, 2018). As a result, one might suspect that the CYRM may not be sensitive enough to reflect improvements in such a short timeframe, especially considering that this measure, except for individual skills, relies on familial and community-level resources. Unfortunately, through the current project, we could not intervene on these levels.

Comparing teacher and student reports of the RESCUR themes, we can conclude from the mean values that both teachers and the students themselves 
considered student behaviour and attitudes to have changed overall for the better. Despite this similarity, the teacher ratings varied between groups while the student ratings did not. This could be attributed to teachers being more knowledgeable and conscientious regarding the meaning of the learning goals mirrored in the checklist items. As teachers reported in supervision sessions (see Simões et al., 2020) for older students in the WG, the children were more aware of their behaviours and had a more advanced understanding of better behavioural alternatives. However, also according to Simões et al. (2020), the teachers responded that the older students still had difficulties making the better decision (e.g. adequate, adaptative, or responsible decisions) in stressful situations, despite being able to think about the situations afterwards. These older students (late primary school level) responded using the student checklists. Thus, their responses may reflect the process of competency acquisition and may indicate a need for more SEL opportunities (i.e. spending more time in the programme) to translate knowledge into action.

Regarding covariates, risk level demands more explanation. Exposure to adverse life events is a well-known predictor of difficulties in the context of both short- and long-term child development (Suntheimer \& Wolf, 2020). Our analyses of the teacher and student measures showed that risk had a strong positive association with difficulties and negative associations with prosocial behaviour, quality of life, and resilience-related competencies. As preventive research shows, socioemotional competence is crucial for healthy development and can mitigate the negative effects of risk exposure (Domitrovich et al., 2017). Future studies should investigate how the implementation of this curriculum affects children with different risk levels and if it is necessary to calibrate dosage to the risk level.

The results showed RESCUR had a positive impact on a set of outcomes. Leppin et al. (2014) stated that resilience-building programmes were expected to have effects on well-being-related outcomes. The systematic review conducted by Fenwick-Smith et al. (2018) provides evidence that universal primary school-based mental health promotion programmes positively affect student abilities. Beyond providing academic content, schools that provide opportunities for resilience development may be more effective in supporting a diverse array of children across many different domains of their lives (Ungar et al., 2019). Altogether, our findings are in line with the literature and support the advantages of implementing resilience-promotion programmes at school. In order to adjust for discrepancies and provide additional evidence of the impact of RESCUR, future studies should use the randomised controlled trial framework and include different age groups and risk levels with measures from different sources (i.e. students, parents, and teachers).

We should note several limitations of this study. First, teachers were tasked with implementing the intervention as well as evaluating the children due to human resource constraints. However, this could have introduced a source of error. Specifically, a positive response bias could have affected the teachers' reports of the children's behaviour and social competencies, which could explain why the teachers in the AIG tended to report greater improvements compared to teachers 
in the WG (Hanisch et al., 2020). Nevertheless, the collaborative relationship between teachers and teacher trainers during the training and subsequent supervision sessions may have reduced this potential bias, resulting in a more reliable measure that was less affected by social desirability bias and other influential factors. During those sessions, teachers also received information regarding assessment. Nonetheless, in future studies, it will be important to assess the RESCUR impact with blinded external evaluators that can assess students' behavioural expression and socioemotional competencies more reliably.

Second, the sample was not randomised because of logistical constraints and teacher availability, though this also represents real-life implementation conditions. Thus, the intervention, as well as the assessment procedure, may present low internal validity but high ecological validity, which increases the probability of finding these results in real-world school contexts (Andrade, 2018; Hanisch et al., 2020).

Third, RESCUR checklists for both teachers and students were filled out only once, foregoing a pre-post comparison. Because the checklists were used in the context of change, teachers and students only filled them out after the theme implementation; consequently, missing data were extensive, which prevented data imputation. Thus, our results must be interpreted with caution. In addition, the measure has not been validated. Nevertheless, the RESCUR checklist is an important measure that supports the implementation process. In the classroom setting, it helps the teacher and students gain awareness about learning outcomes that were the focus of previous sessions and how they affected their behaviour (Cefai et al., 2015). The measure of overall risk may also present content validity, sensitivity, and reliability problems, since it was based on a single item. Nevertheless, some studies have pointed out that single-item measures can be appropriate for assessing some constructs, especially when fatigue could be an issue (Ahmad et al., 2014, Gardner et al., 1998).

Some strengths of this study merit comment, including its robust sample size, involvement of schools in poor and vulnerable areas, and exploration of the impact of RESCUR on children in primary schools (which has not yet been done). The RESCUR programme showed efficacy for reducing mental health difficulties and increasing prosocial behaviours. Moreover, RESCUR participants showed an increase in well-being. Being able to deal with and overcome challenges and adversities is key to children's successful, positive, and healthy development and their ability to accomplish numerous life tasks. This study shows that RESCUR, a universal curriculum for resilience promotion in preschool and primary school, is an intervention with the potential to improve a child's mental health, school achievement, and resilience-related competencies.

\section{Acknowledgements}

All teachers, students, families and professionals involved in the project. 


\section{Declaration of conflicting interests}

The author(s) declared no potential conflicts of interest with respect to the research, authorship, and/or publication of this article.

\section{Funding}

The author(s) disclosed receipt of the following financial support for the research, authorship, and/or publication of this article: The consortium between six European universities that developed RESCUR Curriculum, funded by the EU Comenius Program. The Portuguese National Agency for Scientific and Technological Culture (Ciência Viva) funded this study through the grant INT-338. The Portuguese National Foundation for Science and Technology (SFRH/BD/126304/2016) supported this work through a grant assigned to ACS.

\section{ORCID iDs}

Celeste Simões (D) https://orcid.org/0000-0003-0229-1422

Anabela C. Santos (D) https://orcid.org/0000-0001-7963-8397

João R. Daniel (D) https://orcid.org/0000-0001-6609-2014

\section{Supplemental material}

Supplementary material for this article is available online.

\section{References}

Ahmad, F., Jhajj, A. K., Stewart, D. E., Burghardt, M., \& Bierman, A. S. (2014). Single item measures of self-rated mental health: A scoping review. BMC Health Services Research, 14, 398. https://doi.org/10.1186/1472-6963-14-398

Andrade, C. (2018). Internal, external, and ecological validity in research design, conduct, and evaluation. Indian Journal of Psychological Medicine, 40, 498-499. https://doi.org/ 10.4103/IJPSYM.IJPSYM_334_18

Brownlee, K., Rawana, J., Franks, J., Harper, J., Bajwa, J., O’Brien, E., \& Clarkson, A. (2013). A systematic review of strengths and resilience outcome literature relevant to children and adolescents. Child and Adolescent Social Work Journal, 30, 435-459. https:// doi.org/10.1007/s10560-013-0301-9

Carroll, A., Houghton, S., Forrest, K., McCarthy, M., \& Sanders-O'Connor, E. (2020). Who benefits most? Predicting the effectiveness of a social and emotional learning intervention according to children's emotional and behavioural difficulties. School Psychology International, 41, 197-217. https://doi.org/10.1177/0143034319898741

Cefai, C., Arlove, A., Duca, M., Galea, N., Muscat, M., \& Cavioni, V. (2018). RESCUR surfing the waves: An evaluation of a resilience programme in the early years. Pastoral Care in Education, 36, 189-204. https://doi.org/10.1080/02643944.2018.1479224

Cefai, C., Cavioni, V., Bartolo, P., Simoes, C., Miljevic-Ridicki, R., Bouilet, D., Pavin Ivanec, T., Matsopoulos, A., Gavogiannaki, M., Zanetti, M. A., Galea, K., Lebre, P., Kimber, B., \& Eriksson, C. (2015). Social inclusion and social justice. Journal for Multicultural Education, 9, 122-139. https://doi.org/10.1108/JME-01-2015-0002

Cefai, C., Matsopoulos, A., Bartolo, P., Galea, K., Gavogiannaki, M., Zanetti, M. A., Renati, R., Cavioni, V., Ivanec, T. P., Saric, M., Kimber, B., Eriksson, C., Simoes, C., 
\& Lebre, P. (2014). A resilience curriculum for early years and primary schools in Europe: Enhancing quality education. Croatian Journal of Education, 16, 11-32.

Collaborative for Academic, Social, and Emotional Learning. (2003). Safe and sound: An educational leader's guide to evidence-based social and emotional learning (SEL) programs.

Corcoran, R. P., Cheung, A. C. K., Kim, E., \& Xie, C. (2018). Effective universal schoolbased social and emotional learning programs for improving academic achievement: A systematic review and meta-analysis of 50 years of research. Educational Research Review, 25, 56-72. https://doi.org/10.1016/j.edurev.2017.12.001

Domitrovich, C. E., Durlak, J. A., Staley, K. C., \& Weissberg, R. P. (2017). Social-emotional competence: An essential factor for promoting positive adjustment and reducing risk in school children. Child Development, 88, 408-416. https://doi.org/10. $1111 /$ cdev. 12739

Dray, J., Bowman, J., Campbell, E., Freund, M., Wolfenden, L., Hodder, R. K., McElwaine, K., Tremain, D., Bartlem, K., Bailey, J., Small, T., Palazzi, K., Oldmeadow, C., \& Wiggers, J. (2017). Systematic review of universal resilience-focused interventions targeting child and adolescent mental health in the school setting. Journal of the American Academy of Child and Adolescent Psychiatry, 56, 813-824. https://doi. org/10.1016/j.jaac.2017.07.780

Durlak, J. A., Weissberg, R. P., Dymnicki, A. B., Taylor, R. D., \& Schellinger, K. B. (2011). The impact of enhancing students' social and emotional learning: A meta-analysis of school-based universal interventions. Child Development, 82, 405-432. https://doi.org/10. $1111 /$ j.1467-8624.2010.01564.x

Fenwick-Smith, A., Dahlberg, E. E., \& Thompson, S. C. (2018). Systematic review of resilience-enhancing, universal, primary school-based mental health promotion programs. BMC Psychology, 6, 30. https://doi.org/10.1186/s40359-018-0242-3

Ferreira, L. (2014). Associações entre a resiliência, a autocompaixão e a orientação temporal na adolescência [Associations between resilience, self-compassion and temporal orientation in adolescence] [Unpublished master's thesis]. University of Coimbra.

Fleitlich, B., Loureiro, M. J., Fonseca, A., \& Gaspar, F. (2004). Strengths and dificulties Questionaire-Portuguese version [Questionário do SDQ, versão traduzida e adaptada Para a população Portuguesa (SDQ-Por)]. http://www.sdqinfo.com/d23ahtlm

Forbes, S., \& Fikretoglu, D. (2018). Building resilience: The conceptual basis and research evidence for resilience training programs. Review of General Psychology, 22, 452-468. https://doi.org/10.1037/gpr0000152

Gardner, D. G., Cummings, L. L., Dunham, R. B., \& Pierce, J. L. (1998). Single-item versus multiple-item measurement scales: An empirical comparison. Educational and Psychological Measurement, 58, 898-915. https://doi.org/10.1177/ 0013164498058006003

Hanisch, C., Eichelberger, I., Richard, S., \& Doepfner, M. (2020). Effects of a modular teacher coaching program on child attention problems and disruptive behavior and on teachers' self-efficacy and stress. School Psychology International, 41, 543-568. https:// doi.org/10.1177/0143034320958743

Harnett, P. H., \& Dadds, M. R. (2004). Training school personnel to implement a universal school-based prevention of depression program under real-world conditions. Journal of School Psychology, 42, 343-357. https://doi.org/10.1016/j.jsp.2004.06.004 
Kassis, W., Artz, S., Maurovic, I., \& Simões, C. (2018). What doesn't kill them doesn't make them stronger: Questioning our current notions of resilience. Child Abuse \& Neglect, 78, 71-84. https://doi.org/10.1016/j.chiabu.2017.12.011

Kuznetsova, A., Brockhoff, P. B., \& Christensen, R. H. B. (2016). Package 'ImerTest': Tests in linear mixed effects models [Computer software]. https://cran.r-project.org/web/pack ages/lmerTest/lmerTest.pdf

Larkin, H., Shields, J. J., \& Anda, R. F. (2012). The health and social consequences of adverse childhood experiences (ACE) across the lifespan: An introduction to prevention and intervention in the community. Journal of Prevention \& Intervention in the Community, 40, 263-270. https://doi.org/10.1080/10852352.2012.707439

Leppin, A. L., Bora, P. R., Tilburt, J. C., Gionfriddo, M. R., Zeballos-Palacios, C., Dulohery, M. M., Sood, A., Erwin, P. J., Brito, J. P., Boehmer, K. R., \& Montori, V. M. (2014). The efficacy of resiliency training programs: A systematic review and metaanalysis of randomised trials. PLoS One, 9, e111420. https://doi.org/10.1371/journal. pone. 0111420

Liebenberg, L., Ungar, M., \& LeBlanc, J. C. (2013). The CYRM-12: A brief measure of resilience. Canadian Journal of Public Health= Revue Canadienne de Sante Publique, 104, e131-e135. https://doi.org/10.1007/BF03405676

Masten, A. S. (2018). Resilience theory and research on children and families: Past, present, and promise. Journal of Family Theory \& Review, 10, 12-31. https://doi.org/10.1111/jftr. 12255

Matos, M. G., Gaspar, T., Ferreira, M., Tomé, G., Camacho, I., Reis, M., Melo, P., Simões, C., Machado, R., \& Ramiro, L. (2012). Keeping a focus on self-regulation and competence: "Find your own style", a school-based program targeting at risk adolescents. Journal of Cognitive and Behavioral Psychotherapies, 12, 39-48.

Matos, M. G., Gaspar, T., \& Simões, C. (2012). Health-related quality of life in Portuguese children and adolescents. Psicologia: Reflexão e Crítica, 25, 230-237. https://doi.org/10. 1590/S0102-79722012000200004

Matos, M. G., \& Simões, C. (2016). From positive youth development to youth's engagement: The dream teens. International Journal of Educational Education, 8, 4-18.

Matsopoulos, A., Gavogiannaki, M., \& Griva, A. M. (2020). Parents' perceptions and evaluation of the implementation of a resilience curriculum in Greek schools. International Journal of School \& Educational Psychology, 8, 104-118. https://doi.org/ $10.1080 / 21683603.2020 .1724576$

R Core Team. (2020). R: A language and environment for statistical computing [Computer software]. R Foundation for Statistical Computing. https://www.R-project.org/

Rich, B. A., Shiffrin, N. D., Cummings, C. M., Zarger, M. M., Berghorst, L., \& Alvord, M. K. (2019). Resilience-based intervention with underserved children: Impact on selfregulation in a randomized clinical trial in schools. International Journal of Group Psychotherapy, 69, 30-53. https://doi.org/10.1080/00207284.2018.1479187

Robitzsch, A., \& Grund, S. (2021). miceadds: Some Additional Multiple Imputation Functions, Especially for 'mice'. [Computer software] R package version 3.11-6. https://CRAN.R-project.org/package $=$ miceadds

Simões, C. (2015). Os programas de mudança: A resiliência [The changing programs: Resilience]. In M. G. Matos (Ed.), Adolescentes em navegação segura por água desconhecidas [Adolescents in safe navigation through unknown waters] (pp. 237-240). Coisas de ler. 
Simões, C., Lebre, P., Santos, A., Branquinho, C., Gaspar, T., \& Matos, M. G. (2020). Resiliência nas escolas: Currículo Europeu para a Resiliência (RESCUR) em Portugal [Resilience in schools: European Curriculum for Resilience (RESCUR) in Portugal]. In A. Pessoa, \& S. Koller (Eds.), Resiliência \& Educação: Perspectivas teóricas e práticas [Resilience \& Education: Theoretical and practical perspectives] (pp. 315-336). Editora Vetor.

Suntheimer, N. M., \& Wolf, S. (2020). Cumulative risk, teacher-child closeness, executive function and early academic skills in kindergarten children. Journal of School Psychology, 78, 23-37. https://doi.org/10.1016/j.jsp.2019.11.005

Ungar, M., Connelly, G., Liebenberg, L., \& Theron, L. (2019). How schools enhance the development of young people's resilience. Social Indicators Research, 145, 615-627. https://doi.org/10.1007/s11205-017-1728-8

Ungar, M., Russell, P., \& Connelly, G. (2014). School-based interventions to enhance the resilience of students. Journal of Educational and Developmental Psychology, 4, 66-83. https://doi.org/10.5539/jedp.v4n1p66

van Buuren, S. (2011). Multiple imputation of multilevel data. In J. J. Hox, \& J. K. Roberts (Eds.), The handbook of advanced multilevel analysis (pp. 173-196). Routledge.

van Buuren, S., \& Groothuis-Oudshoorn, K. (2011). Mice: Multivariate imputation by chained equations in R. Journal of Statistical Software, 45, 1-67. https://www.jstatsoft. org/v45/i03/.

Weissberg, R. P., \& Cascarino, J. (2013). Academic learning + social-emotional learning = national priority. Phi Delta Kappan, 95, 8-13. https://doi.org/10.1177/ 003172171309500203

Weissberg, R. P., Durlak, J. A., Domitrovich, C. E., \& Gullotta, T. P. (2015). Social and emotional learning: Past, present, and future. In J. A. Durlak, C. E. Domitrovich, R. P. Weissberg, \& T. P. Gullotta (Eds.), Handbook for social and emotional learning (pp. 3-19). Guilford.

World Health Organization. (2017). Strengthening resilience: A priority shared by Health 2020 and the Sustainable Development Goals. WHO Regional Office for Europe. http:// www.euro.who.int/_data/assets/pdf_file/0005/351284/resilience-report-20171004-h 1635.pdf

Xiong, J., Hai, M., Wang, J., Li, Y., \& Jiang, G. (2020). Cumulative risk and mental health in Chinese adolescents: The moderating role of psychological capital. School Psychology International, 41, 409-429. https://doi.org/10.1177/0143034320934524

Zins, J., Bloodworth, M., Weissberg, R., \& Walberg, H. (2004). The scientific base linking social and emotional learning to school success. In J. E. Zins, R. P. Weissberg, M. C. Wang \& H. J. Walberg (Eds.), Building academic success on social and emotional learning: What does the research say? (pp. 3-22). Teachers College Press.

\section{Author biographies}

Celeste Simões, PhD, is Associate Professor with Aggregation at the Faculty of Human Kinetics, University of Lisbon. She has a degree in Special Education and Rehabilitation, a master's in Social Psychology, a PhD in Special Education, in the area of risk behaviors in adolescence and Aggregation in Education Sciences. She is a Member of the Study Center for Education and Health Promotion (FMH-UL) and the Environmental Health Institute Research Center from the Faculty of Medicine of Lisbon. Her main areas of interest are social and emotional 
competences, resilience, health promotion and education, and risk behaviors in adolescence. In this field, she has coordinated several national and international projects.

Anabela C. Santos is a PhD student in Educational Sciences - Expertise in Health Education at the Faculty of Human Kinetics, University of Lisbon (FMH-UL). Her research project focuses on socioemotional competences and internal resilience assets on school outcomes, such as student engagement and performance, including low and high-risk samples. She is a Member of the Study Center for Education and Health Promotion (FMH-UL) and ISAMB (Faculty of Medicine-UL). She is a psychomotor therapist with experience both in clinical setting and children residential care homes. She collaborated with international projects focussing on socioemotional competences, resilience and teachers training.

Paula Lebre, $\mathrm{PhD}$, is a Lecturer in Psychomotor Rehabilitation Courses at the Faculty of Human Kinetics, Lisbon University (FMH-UL), Portugal. She is a Member of the Study Center for Education and Health Promotion (FMH-UL), involved in national and international research projects on mentoring, socioemotional learning and resilience. Since 1994 has been collaborating, within community extension activities, in community programs for individuals with disabilities. She is a researcher at Institute of Ethnomusicology (INET-md) -(FMH-UL), developing research on the use of dance in psychomotor interventions in preventive, therapeutic and inclusive dance for individuals with neuro developmental disorders, mental health problems and dementia.

João R. Daniel, PhD, is a Post-Doc Researcher in William James Center for Research, ISPA - Instituto Universitário, Portugal. He has a degree in Biology (5-year degree) from the Faculty of Sciences of the University of Lisbon and a post-graduation in Probability and Statistics from the same faculty. He has a PhD degree in Psychology (specializing in Ethology), supported by an FCT individual studentship (Portuguese Science and Technology Foundation). He has taught graduate and undergraduate courses in Quantitative and Qualitative Research Methods in Psychology, and short courses in statistical models for social network analysis and $\mathrm{R}$ programming language.

Cátia Branquinho, $\mathrm{PhD}$, is a Clinical and Health Psychologist, Doctor in Educational Sciences, specialized in Health Education by the Faculty of Human Kinetics, University of Lisbon. Researcher of the Aventura Social team. Member of the international network Health Behavior in School-aged Children/World Health Organization, with special focus on youth engagement, susbtance use and addictive behaviors, new technologies and interpersonal violence. Co-chair of youth engagement group. 
Tânia Gaspar, PhD in Psychology, Master Degree in Public Health, Specialization - Health Promotion and Prevention and Graduated in Clinical Psychology, is President of Aventura Social Association and Director of Psychology and Education Sciences Institute in Lisbon Lusíada University. She is Director of Journal of Child and Adolescent Psychology and Member of Aventura Social Team Faculdade de Motricidade Humana/UTL. She is Deputy PI and Member of International Study Health Behaviour School Aged Children/WHO Group. She Coordinates the Research Group "Quality of Life, Psychosocial Intervention and Inclusion" at Centro Lusíada Research in Social Work and Social Intervention and is Member of ISAMB, research Centre Medicine Faculty/Lisbon University.

Margarida G. de Matos, PhD, is a Clinical and Health Psychologist, Full Professor at the Faculty of Human Kinetics, Lisbon University (FMH-UL), Portugal. She is a Member of the Study Center for Education and Health Promotion (FMH-UL), involved in national and international research projects on Health promotion, Public policies, Youth positive development, Youth social engagement and Psychotherapy. She is involved in 4 PhD Study programs: Health Education; Nursing; Environmental Health and Sciences of Sustainability (all 4 at University of Lisbon). She is a senior researcher and research group leader (Supportive environments) at Institute of Environmental Health/Medical School/University of Lisbon. She is the representative of the Portuguese Association of Psychologist at the European federation of Psychology Associations (EFPA), being the convenor of the Board of Promotion and Prevention. She has an extensive experience of research projects, project evaluation, and students tutoring. She has an extensive list of national and international publications: research papers, chapters, books. 